\title{
Revolución íntima y revolución universal: una lectura de Vuelos de victoria de Ernesto Cardenal
}

\author{
Victoria Famin ${ }^{\bullet}$ \\ Universitè Lumière Lyon 2
}

\begin{abstract}
Resumen
Este trabajo propone una lectura del poemario Vuelos de victoria (1984) del poeta nicaragüense Ernesto Cardenal, teniendo en cuenta los principios del exteriorismo al que el autor adhiere y sus propias exigencias poéticas. En tal sentido, se tratará de identificar las particularidades de estos poemas concebidos en estrecha relación con el contexto político y social de la Nicaragua de finales de los años 80 . Siguiendo las líneas de la poesía impura proclamada por Neruda, Cardenal asume un rol de poeta profeta y lleva adelante en este poemario una revolución poética a la vez íntima y universal.

Palabras clave:

- Ernesto Cardenal · exteriorismo · revolución · poesía impura · Nicaragua
\end{abstract}

\begin{abstract}
This work proposes a reading of the collection of poems Flights of Victory (Vuelos de Victoria) (1984) by the Nicaraguan poet Ernesto Cardenal, considering the principles of Exteriorism that the author concurs with and his own poetic demands. In this regard, we will try to identify the special features of these poems, which were conceived in close relationship with Nicaragua's political and social context from the late 1980's. Following the lines of the impure poetry proclaimed by Neruda, Cardenal assumes the role of a prophet poet, and in this collection he brings an intimate and universal poetic revolution.

\section{Key words:}

- Ernesto Cardenal · Exteriorism · Revolution - impure poetry Nicaragua
\end{abstract}

\footnotetext{
- Doctora en Literatura Francesa y Comparada de la Universidad Paris-Sorbonne y maître de conférences en la Université Lumière Lyon 2 (Francia). Es especialista en literatura hispanoamericana y francófona del Caribe. Sus trabajos abordan tanto la especificidad de estas literaturas como sus puntos en común. Ha publicado numerosos artículos sobre autores como Édouard Glissant, Alejo Carpentier, Jean-Claude Fignolé, entre otros.
} 
Ernesto Cardenal puede ser considerado actualmente como una de las figuras mayores de la literatura latinoamericana, no sólo por la riqueza de su vasta obra, sino también porque encarna al poeta mítico que ha sabido integrar su trabajo poético y su vida con una absoluta coherencia. Al iniciar su trabajo de poeta en los años 1940, integrando la "Generación del 40» junto a Ernesto Mejía Sánchez y Carlos Martínez Rivas, Cardenal comienza un trabajo de reflexión profunda sobre la posibilidad de escribir una poesía que pueda estar no solamente íntimamente ligada a la realidad de su Nicaragua natal, sino también en perfecto acorde con sus convicciones religiosas, políticas y sociales. Este proyecto que guía de manera insoslayable su producción poética, no supone una ruptura con los movimientos vanguardistas que emergen en las primeras décadas del siglo XX en América Latina y en Nicaragua en particular. Por el contrario, y como lo explica Maria Enrica Castiglione, Cardenal manifiesta el deseo de inscribir su palabra poética en la continuidad de la poética nicaragüense, pero introduciendo este nuevo acercamiento de la poesía a la realidad contemporánea (Castiglione, 1990:4). Así entonces comienza a forjar, desde sus primeros poemas, las bases del movimiento que se llamó exteriorismo, intentando arraigar la poesía a un referente extra poético, sin por ello relegar a un segundo plano el trabajo minucioso sobre el lenguaje.

$\mathrm{Su}$ figura adquiere también una importancia capital porque Cardenal combina tres pasiones que guían su palabra sin provocar tensiones. Como poeta, sacerdote y militante del Frente Sandinista de Liberación Nacional, Cardenal logra una palabra única y potente, capaz de vehicular su pensamiento sin traicionar ninguna de sus preocupaciones. La calidad poética de su lenguaje no se ve amenguada por la necesidad de decir una realidad urgente, ardiente, que lo obsesiona y que guía al mismo tiempo su proceder. En este sentido abandona la "poesía pura" para concebir la "poesía sin pureza» que Pablo Neruda reivindica en Caballo verde para la poesía: "Así es la poesía que buscamos, gastada como por un ácido por los deberes de la mano, penetrada por el sudor y el humo, oliente a orina y a azucena, salpicada por las diversas profesiones que se ejercen dentro y fuera de la ley» (1935-1936:5). La poesía cardenaliana es una poesía estrechamente relacionada con el mundo de los hombres, con lo cotidiano que marca la vida de los nicaragüenses. Como lo afirma Sonia Mereles Olivera, «Cada obra de Ernesto Cardenal es un producto de su experiencia humana y del desarrollo de sus valores de acuerdo a la circunstancia histórica» (Mereles Olivera, 2003:119). La obra de este poeta acompaña los movimientos de la sociedad nicaragüense y se inscribe en un momento álgido de su historia.

La poesía impura que Pablo Neruda reivindica surge como una necesidad en un contexto socio político bien preciso: el de la Segunda República y el estallido de la Guerra Civil española. En este marco de efervescencia política, la palabra poética no puede mantenerse al margen del mundo social. De la misma manera, la obra poética de Ernesto Cardenal se desarrolla en un contexto de paulatina toma de consciencia de la necesidad de luchar contra la opresión que sufre el pueblo, 
no solamente en Nicaragua sino en toda América Latina e incluso en el contexto de las luchas anticolonialistas de África. La revolución cubana y las guerras de independencia de los países africanos funcionan como un verdadero motor para las sociedades oprimidas de América Latina y Ernesto Cardenal se muestra particularmente sensible frente a los movimientos que se gestan en Nicaragua. Pero otro fenómeno socio-cultural interviene en el desarrollo cardenaliano del exteriorismo: se trata de la influencia de la Teología de la Liberación a la cual el poeta y sacerdote adhiere plenamente. Inspirado por las discusiones del Concilio Vaticano II, Ernesto Cardenal funda la comunidad de Solentiname en 1965, para vivir la verdadera unión con Dios, que pasa inevitablemente por la unión entre los hombres y que lleva a la revolución necesaria (Cardenal, 1978:165-167).

En esta serie de compromisos políticos, sociales y espirituales, la poesía de Ernesto Cardenal y su exteriorismo tienen un rol fundamental. Como lo afirma Iván Uriarte, «el exteriorismo ha jugado un papel importante en el desarrollo de la actual poesía revolucionaria nicaragüense, que va desde los manifiestos del Frente Ventana a los trabajos críticos de Ricardo Morales y la teoría y práctica literaria de Cardenal» (2000:73). Así, la obra cardenaliana es irrigada por el pensamiento del autor y no se limita simplemente a expresarlo sino que lo sublima gracias a la fuerza del lenguaje poético.

Si bien los poemarios de Cardenal son numerosos y contribuyen cada uno en la construcción de una palabra poética personal, Vuelos de victoria, publicado en 1984, será el objeto de estudio del presente trabajo. Este poemario tiene la particularidad de presentar una cierta madurez de la escritura del poeta, relacionada con el aspecto diacrónico que le permite tener una visión retrospectiva de la revolución. Este volumen se construye como un díptico que presenta el antes y el después de la revolución, poniendo el acento en la euforia y el renacimiento que trae la victoria. Con una fuerte dimensión metapoética, los poemas de Vuelos de victoria ponen de manifiesto no solamente la capacidad del poeta de proponer una mirada crítica del proceso revolucionario sino también la relación que establece entre sus convicciones religiosas y su accionar político. Y lo que resulta aún más importante, la función indispensable de la poesía y del poeta durante y después de la revolución. En esta etapa de análisis y conclusiones, los poemas de Vuelos de victoria llevan a Cardenal a interrogarse sobre su propio papel de poeta en tiempos de revuelta y sobre el impacto que esta revolución tiene en su vida. En este sentido convendría preguntarse en qué medida la revolución poética de Ernesto Cardenal puede ser considerada como íntima y universal al mismo tiempo y qué repercusiones tiene esta doble revolución en la práctica poética del autor.

\section{El poeta como profeta de la revolución}

Ernesto Cardenal asume en los poemas de Vuelos de victoria un rol de poeta como guía del pueblo y lo hace explícitamente. En este sentido es posible identificar la concepción del poeta vidente que Victor Hugo define en «Fonction du poète» (1840), con la clarividencia y la lucidez necesarias para guiar al pueblo en las tinieblas, llevarlo hacia la luz. El poeta se vuelve así profeta de un futuro luminoso y muestra a los 
hombres el camino que deben tomar. En el contexto de la revolución sandinista, los poemas de Cardenal hacen oír la voz del poeta como profeta de la revolución. Esta voz se alza para llamar a los campesinos a la lucha, no solamente por medio de las armas sino también a través de la poesía. En el poema "Amanecer", el poeta se dirige a Pancho Nicaragua, que representa colectivamente al campesinado nicaragüense: «Levantate Pancho Nicaragua, cogé el machete/Hay mucha yerba mala que cortar/Cogé el machete y la guitarra» (1984:9). El voseo que emplea el poeta refuerza la idea de una proximidad con los campesinos a quienes llama a la lucha. La "yerba mala» representa tanto la faena diaria del campesino como el mal que acosa y oprime al pueblo. Pero lo que retiene la atención en estos versos es la combinación del machete y la guitarra, siendo el primer elemento símbolo de la lucha armada y la segundo de la poesía. El arte acompaña la lucha y la completa, en la visión de Ernesto Cardenal. Por eso, en su rol de guía del pueblo, el poeta no se contenta con alzar su voz para cantar la revolución sino que incita al campesinado a expresar su lucha artísticamente, lo que fue practicado en particular en la comunidad de Solentiname.

La figura del poeta como profeta de la revolución aparece en los poemas no como la simple decisión del poeta de adjudicarse un rol. Es el resultado de un doble proceso que supone, por un lado la aceptación de la función de guía, pero por el otro un reconocimiento de parte del campesinado. Por esta razón, en la mayoría de los poemas de este volumen es posible identificar estructuras dialógicas, en las que el poeta se dirige al pueblo y en ciertos casos, la palabra del pueblo surge de manera más o menos directa. Es el caso del poema "La llegada», en el que un intercambio furtivo con un agente del aeropuerto revela la inmensa connivencia que existe entre el poeta y la población, y la confianza que deposita la gente en la figura del sacerdote-poeta: «el muchacho que me registra hace como que registra/ Sin registrar nada y me ha dicho en voz baja: "Reverendo"» (Cardenal, 1984:15). El hecho de que el joven se dirija al poeta llamándolo «Reverendo» pone en evidencia no solamente el respeto que suscita su figura sino también la identidad religiosa de Cardenal, indisociable de su figura de poeta y de militante. En efecto, para la población es ante todo un sacerdote que intenta acercar la palabra de Dios a la vida de la gente y alimentar así el movimiento revolucionario de liberación. En este sentido el término profeta se arraiga en la tradición cristiana porque anuncia un futuro luminoso que está previsto por Dios.

En los poemas de Vuelos de victoria, el diálogo se instala también con Dios, y en este sentido el poeta recuerda su voluntad de conjugar los diferentes aspectos de su pensamiento y de su misión, como él la concibe. Es el caso en particular del poema «Visión mística de las letras FSLN», en el que el poeta refuerza esa idea de diálogo con Dios transcribiendo el mensaje divino:

Entonces desde el auto miré las letras grandes sobre el cerro

Y dentro de mí me habló Dios:

Mirá lo que yo hice por vos, 
Por tu pueblo, pues.

Mirá esas letras, y no dudes de mí, tené fe

Hombre de poca fe

Pendejo (1984:47)

Una vez más, el poeta recurre al voseo para marcar la proximidad absoluta con su interlocutor, procedimiento que se vuelve aún más fuerte en este caso en que se trata de un mensaje divino. En esta imprecación Dios no duda en utilizar la palabra "pendejo», de un registro más que familiar, para actualizar lingüísticamente el reproche evangélico de Jesús. Pero más allá de la legitimación religiosa que el poeta intenta lograr como profeta que debe guiar al pueblo, estos versos intentan respaldar espiritualmente la revolución sandinista como un designio divino para el pueblo de Dios.

En estos poemas Ernesto Cardenal logra el desafío preciso de su exteriorismo que es doblemente complejo, porque debe mantener la exigencia poética abordando cuestiones íntimamente ligadas con la realidad del pueblo campesino de Nicaragua, pero que en ese mismo movimiento debe lograr la unión con Dios en una espiritualidad cristiana activa y combativa. Paul Borgeson afirma al respecto que:

El verso profético de Cardenal integra el interés social como la creencia espiritual. En estas obras, así, la poesía sirve tanto a la fe como a las preocupaciones más mundanas. Se logra reunir la tradición de poesía política en Hispanoamérica (como en Neruda y Vallejo) con la perspectiva de los profetas bíblicos y los místicos españoles. Su verso profético es seguramente una de las hazañas más señaladas de Cardenal. (1984:122)

En Vuelos de victoria la poesía profética de Ernesto Cardenal se construye gracias a un dispositivo estructural que divide el poemario en dos partes. La primera reúne los poemas que evocan la lucha del pueblo, y la segunda, la nueva vida de Nicaragua después del triunfo de la revolución. Si en el contexto histórico en el que es publicado el volumen el cambio está efectivamente siendo experimentado por la sociedad nicaragüense, la palabra del poeta conserva su aspecto profético ya que intenta proyectar la revolución en un futuro perfeccionador. Cada mínimo gesto de cambio es puesto en valor por el poeta gracias a una proyección que lo resignifica, aumentando su dimensión y así su relevancia. Borgeson analiza esta capacidad profética del verso cardenaliano asociándola justamente al proceso de interpretación de cada elemento histórico: «El poeta-profeta, como guía y mediario, interpreta los sucesos, infundiéndoles un sentido y una continuidad que combaten dos males corrientes: el sentido de soledad y el sinsentido del existir» (1984: 139). La poesía profética de Cardenal funciona en un doble sentido: el que lleva a un futuro de realización y de satisfacción de una sociedad nicaragüense liberada y el que retrotrae al pasado de lucha, de sufrimiento y de sacrificio. Esta mirada retrospectiva intenta no sólo rendir homenaje a los héroes anónimos de la revolución sino también recordar cada gesto individual y colectivo realizado. Esta palabra sobre el pasado es profética porque la interpretación de la lucha permite revalorizar la idea de una revolución lograda. "El sentido de soledad y el sinsentido del existir» que menciona Borgeson y que podrían surgir después de la victoria, son conjurados por el poeta profeta que no cesa de velar por el proyecto de toda una sociedad.

El poeta como profeta de la revolución no solamente debe guiar al pueblo en su lucha sino también mantener presente en el pensamiento de la comunidad los 
ideales políticos, sociales y espirituales que orientan su lucha. En este sentido, su función después de la victoria consiste en recordar y perennizar gracias a su palabra poética las bases conceptuales del movimiento revolucionario sandinista. En el poema «A Donald y a Elvis» esta función aparece claramente: «que la resurrección no eran las quirinas saliendo de las tumbas/sino la supervivencia de la conciencia en los otros» (Cardenal, 1984:51). En estos versos la resurrección aparece asimilada a la revolución y la imagen física de la quirinas, es decir los esqueletos, saliendo de las tumbas se opone a la noción abstracta pero necesaria de la conciencia de la revolución en el seno del pueblo nicaragüense. Este es uno de los principales objetivos de la poesía profética cardenaliana después de la victoria.

\section{Revolución íntima y revolución universal}

La revolución sandinista tiene un lugar central en Vuelos de victoria, porque estructura cronológicamente el poemario y constituye el tema subyacente de todos los poemas. Pero el poeta no se contenta con anunciar, promover y describir la revolución. Se trata para él de un tema de reflexión profundo, que lo lleva a cuestionar la posibilidad de concebir la revuelta del pueblo nicaragüense como una revolución multifacética. El poeta presenta la problemática de la concepción de la revolución con una mirada dicotómica, que induce a una aparente disyuntiva.

La revolución cardenaliana parece oscilar entre la intimidad y la universalidad. El carácter íntimo de la poesía sobre la revolución está dado por la voluntad de arraigar la palabra poética en lo humano y terreno. En su exteriorismo poético Cardenal evoca las vivencias de los campesinos como hombres y mujeres fortalecidos y fragilizados por los sufrimientos de la carne. La materialidad que los caracteriza está puesta de relieve para poder acentuar el carácter íntimo y humano de la revolución. En este sentido, el poema "Las campesinas del Cuá", construido como un coro femenino de mujeres que sacrifican su vida para proteger a los revolucionarios, está puntuado por las referencias a la intimidad femenina que aparece herida y al mismo tiempo sublimada en el contexto de la revolución: «La Matilde abortó sentada/Cuando toda una noche nos preguntaban por los/Guerrilleros» (1984:12). La evocación de la maternidad truncada como sacrificio íntimo pero altamente simbólico es un procedimiento que tiende a reforzar la idea de una revolución que se logra pagando el precio más alto: el de la propia integridad física. Pero el encabalgamiento que pone de relieve la palabra guerrilleros permite evitar todo pathos excesivo que podría desplazar el tema de la revolución colectiva de su lugar central.

La revolución es íntima también porque el poeta expone en ciertos poemas su cuestionamiento personal, desvelando así sus sufrimientos personales. No se trata solamente de reflexionar sobre su rol de profeta y guía del pueblo, sino de mostrar su fragilidad personal en momentos de dolor al lado de los campesinos guerrilleros: «Primero fue el lago, calmo. Y en él/Mi lugar, lo que fue mi hogar, Solentiname./ (...)/La punta donde estuvo la comunidad. Todo arrasado» (19). En estos versos de "Vuelo sin escala sobre la patria», el poeta evoca la vista del archipiélago de Solentiname, sede de la comunidad que él había fundado y que fue destruida en 
1977 por la Guardia Nacional de Somoza. La evocación de la comunidad, en el segundo verso, acentúa por su ritmo terciario el apego del poeta hacia este grupo humano reunido por una idea de unión espiritual. Los sintagmas «mi lugar» $\mathrm{y}$ «mi hogar» refuerzan la idea de que la revolución es íntima porque atańe a cada uno de los protagonistas, en lo más profundo de su ser. Lo personal y lo colectivo aparecen indisociables en una lucha que es de todos y de cada uno. La idea de comunidad surge en los poemas de Vuelos de victoria gracias a la enumeración acumulativa de los distintos protagonistas de la revuelta, sin por eso anular cada individualidad. Paul Borgeson agrega a esto el elemento espiritual, que está omnipresente en la poética cardenaliana, cuando afirma que:

En resumen, tanto la liberación social y la salvación personal son fenómenos sociales para Cardenal, quien a la manera de los profetas del Antiguo Testamento, niega ninguna separación de la vida religiosa y de la vida en la sociedad. Luego: en su verso definitivo, la preocupación social y la perspectiva religiosa también son inseparables. (1984:115-116)

La revolución es íntima en lo humano y en lo espiritual, pero también lo es en lo que concierne a lo político. Ernesto Cardenal, gracias a procedimientos literarios similares al zoom hacia atrás cinematográfico, logra reposicionar a Nicaragua en América Latina y en el mundo, poniendo de relieve su pequeñez territorial en la escala mundial. Este efecto de óptica refuerza la impresión de intimidad que caracteriza la revolución llevada adelante por el campesinado nicaragüense, en un mundo lleno de complejidades. La revuelta de estos hombres y mujeres parece retraerse a la lucha íntima de una comunidad ínfima del mundo.

Sin embargo, el carácter íntimo de la revolución coexiste en la poética de Cardenal con una idea de universalidad. Con la misma intensidad con la que su mirada focaliza la particularidad de la revolución sandinista, el poeta efectúa el movimiento inverso que le permite poner de manifiesto el aspecto universal del movimiento. Su discurso intenta abarcar paulatina y gradualmente todo lo que rodea a Nicaragua y abrir en ondas concéntricas el movimiento de la revolución.

La naturaleza como medio inmediato de la vida campesina aparece en los poemas de Vuelos de victoria como un personaje que precisa de la revolución para subsistir. Aparece entonces como una protagonista más de la revolución que no es ya una simple decisión sino una verdadera necesidad: «La liberación no sólo la ansiaban los humanos. / Toda la ecología gemía. La revolución / Es también de lagos, ríos, árboles, animales» (Cardenal, 1984:40). La prosopopeya de estos versos y la elección del verbo «gemir» ponen de relieve la concepción de una revolución que se universaliza porque concierne no solamente a los hombres y mujeres de Nicaragua sino al conjunto de la creación divina. Además, el poema "Nueva ecología» evidencia una mirada moderna sobre el respeto del medio ambiente como se respeta la vida humana, dos de las principales promesas de la revolución sandinista que se encamina así hacia lo universal.

La adopción de una mirada globalizadora, con un movimiento de zoom hacia atrás, permite al poeta desarrollar este aspecto universal de la revolución. Evocando los diferentes marcos en los que sitúa una Nicaragua cada vez más pequeńa, aunque no por eso insignificante, el poeta intenta posicionar su revolución poética, política y social, en el universo mismo como espacio último de la existencia. En el poema «Luces», la Vía Láctea aparece como el marco último en el que se inscribe la revolución nicaragüense: 
El cielo lleno, llenísimo de estrellas. La Vía Láctea

Clarísima tras el grueso vidrio de la ventanilla,

Masa blancuzca y rutilante en la noche negra,

Con sus millones de procesos de evoluciones y revoluciones. (...)

La Vía Láctea arriba, y las luces de la revolución de Nicaragua. (23)

El hecho de elegir el espacio cósmico como marco último de la revolución sandinista permite al poeta establecer un paralelismo conceptual entre las revoluciones de los astros y la revolución sandinista, como procesos naturales y necesarios para el equilibrio del universo. El último verso de la cita, construido sobre una estructura binaria, establece, sobre un eje vertical, una conexión directa entre el espacio universal representado por la Vía Láctea y el punto ínfimo e íntimo de la Nicaragua revolucionaria.

Lo íntimo y lo universal aparecen entonces en los poemas de Vuelos de victoria no como dos aspectos dicotómicos y opuestos sino como dimensiones complementarias de una revolución que aparece sublimada por esta naturaleza compleja. Esto redunda en una valorización de la misión de los campesinos guerrilleros y del poeta mismo, que asumen la realización de un destino ineluctable. El poema «En el lago» pone de manifiesto la relación entre la intimidad del guerrillero desconocido y el destino de Nicaragua como componente de la galaxia:

Vengo de ser interrogado por la Corte Militar

$\mathrm{Y}$ pienso en los inmensos mundos sobre nosotros

Una sola galaxia

(si la Tierra fuera como un grano de arroz

La galaxia sería como la órbita de Júpiter).

Y pienso en el compañero «Modesto» en la montaña,

De origen campesino; no se sabe su nombre.

Luchan por cumplir nuestro destino en la galaxia. (16)

Las comparaciones que propone el poeta en los versos cuatro y cinco de la cita le permiten jugar con la cuestión de las dimensiones, dejando entender que todo puede ser universal, independientemente de su tamaño y envergadura. De esta manera, la revolución nicaragüense puede ser considerada universal, no sólo porque se inscribe en un espacio mayor como puede ser la Vía Láctea, sino también porque al formar parte de ella participa en la vida de lo universal.

La toma de conciencia de esta universalidad de la revolución permite tener una cierta confianza en el avenir del pueblo nicaragüense. Saber que la revolución sandinista no hace más que cumplir el designio universal transmite un sentimiento de confianza y de tranquilidad que el poeta intenta vehicular en sus poemas:

Girando en el espacio negro

Dondequiera que vayamos, vamos bien.

Y también

Va bien la Revolución. (45)

El poeta adopta el nosotros de la primera persona del plural para asociarse al pueblo que lucha y animarlo en los momentos de duda. Pero la certidumbre de 
hacer lo correcto trasluce en la construcción de estos versos, en los que el poeta no duda en utilizar el presente de verdad general para reforzar la idea de haber hecho lo correcto. La imagen de la revolución universal se completa en los poemas de Vuelos de victoria con el topos de la luz al que es asociada: "Es contra las tinieblas esta revolución» (25). Las tinieblas de la opresión son disipadas por una luz que se instala en la íntima cotidianeidad del campesino: «Hermano, amaneció. Mirá» (37). El amanecer como símbolo de un renacimiento es una figura fuerte del poemario que oscila constantemente entre el significado íntimo y universal de la revolución.

\section{Poesía toda, poesía total}

Los poemas de Vuelos de victoria son indudablemente la expresión de un compromiso político y social. Constituyen un claro ejemplo de poesía comprometida, pero esto no supone de ninguna manera una negligencia en lo que concierne al trabajo formal y lingüístico del poeta. Muy por el contrario, este poemario pone en evidencia un trabajo profundo sobre el lenguaje poético que permite expresar, sostener y vehicular un mensaje fuerte. En la obra de Ernesto Cardenal poesía, espiritualidad y compromiso social son tres aspectos de un mismo pensamiento, sin que uno se posicione por encima de los otros. En este sentido, la poesía no es un simple modo de expresión sino el instrumento que permite al autor reflexionar y proponer su visión de la revolución al mundo.

Por todas estas razones, no es de extrañar que Cardenal se posicione con respecto al contexto literario en el que evoluciona y adopte el exteriorismo como una concepción de la literatura que puede dar cuenta del aspecto íntimo de la revolución, sin negar su dimensión universal. En su Prólogo a Poesía nueva de Nicaragua, Cardenal lo define de la siguiente manera:

\footnotetext{
El exteriorismo es la poesía creada con las imágenes del mundo exterior, el mundo que vemos y palpamos, y que es, por lo general, el mundo especifico de la poesía. El exteriorismo es la poesía objetiva: narrativa y anecdótica, hecha con los elementos de la vida real y con las cosas concretas, con nombres propios y detalles precisos y datos exactos y cifras y hechos y dichos. En fin, es poesía impura. Poesía que para algunos está más cerca de la prosa que de la poesía, y equivocadamente la han llamado "prosaista», debido a que su temática es tan amplia como la de la prosa. (1974:10)
}

Es importante notar cómo Cardenal en su definición de exteriorismo se acerca claramente a la concepción nerudiana de poesía impura. En tal sentido, Iván Uriarte señala que al igual que Neruda, Cardenal opera en su poesía una trasformación del yo existencial en yo colectivo (2000:179). Al leer los poemas de Vuelos de victoria, sin embargo, es posible identificar las particularidades de la escritura cardenaliana. En efecto, si la cuestión de la proximidad con el mundo campesino es indiscutible, el exteriorismo permite otro procedimiento central también en este volumen que es el de la construcción de una colectividad multitudinaria que sostiene la idea de revolución. En tal sentido, la práctica poética permite a Cardenal reunir la multitud 
de detalles ligados a la vida cotidiana de los hombres y mujeres nicaragüenses para construir una idea de pueblo como unidad en la diversidad. Sonia Mereles Olivera resalta este aspecto del exteriorismo cardenaliano haciendo referencia al aspecto colectivo que predomina en su producción poética: «Ernesto Cardenal bautiza su poesía de "exteriorista" y evade usar el término de "objetiva" pues más bien lo que pretende indicar en ella es el retrato de una consciencia colectiva y no de un conflicto personal» (2003:138). Cuando el poeta evoca un cuestionamiento personal en este poemario, lo hace pensando en su rol en el seno de la colectividad que integra. El destino colectivo prevalece ante todas las otras problemáticas que puedan surgir.

La noción de colectividad supone un gesto de recolección y de acumulación de una gran variedad de materiales humanos que funcionan como los componentes de la comunidad. Esta proximidad con la realidad social está ligada a un momento especial de la historia de Nicaragua, pero no por eso Cardenal se vuelca en la llamada literatura de urgencia. Iván Uriarte evoca este equilibrio que el poeta intenta encontrar en su práctica del exteriorismo, diciendo que se trata de

una poética cuya principal preocupación comenzó a ser un intento tanto de comprensión real de la historia como de comprensión de la realidad social inmediata. Esta poética, conocida con el nombre de Exteriorismo, surge frente a la urgencia de incorporar los más diversos hechos de la realidad, desechando a su vez todo subjetivismo desvinculado de lo factual. Aunque su punto de partida no es el de una poética engagée, la abertura a la realidad que plantea permite la irrupción al hecho social, a la poesía como factor dinámico en la lucha de clases que en ese momento se iniciaba sobre nuevas bases. (2000:70-71)

Si bien hay urgencia en el decir, dicha urgencia no se trasluce en el lenguaje poético cardenaliano, porque cada elemento y cada procedimiento de escritura aparece como un gesto tranquilamente decidido. Esto no es únicamente el resultado de una exigencia poética personal, sino también una necesidad, porque como lo explica Uriarte, la poesía constituye un factor dinámico en el proyecto revolucionario.

El exteriorismo cardenaliano construye una idea de colectividad que engloba a la sociedad nicaragüense oprimida. Para dar fuerza a este actor colectivo de la revolución, el poeta no duda en poner en práctica procedimientos de enumeración y de acumulación, de manera que la proliferación y la concentración de elementos relativos a esta humanidad en sufrimiento pueda apuntalar la construcción poética de la comunidad. Es por esto que en poemas como "Barricada", la enumeración lleva a una idea de unidad popular frente al agresor:

Los que hicieron las tareas importantes,

Y los que hacían las menos importantes;

Esto fue una tarea de todos.

La verdad es que todos pusimos adoquines en la gran barricada.

Fue una tarea de todos. Fue el pueblo unido.

Y lo hicimos. (1984:31)

El «todos» inclusivo que recorre el poema abarca al poeta y a un sinnúmero de militantes que contribuyeron para la revolución. Los dos primeros versos de la cita, construidos como un paralelismo, refuerzan la idea de inclusión como un gesto natural durante la revuelta. 
La idea de unidad está también presentada en el poema "Visión de un rostro", en el que todos los hombres y mujeres de Nicaragua se hacen uno para sostener los logros de la revolución: «y se veía la unidad de todos, / La unidad garantía de la Victoria» (43). La unidad aparece no como la expresión de uno sino como la reunión de todos y en este sentido la poesía de Cardenal necesita ser una poesía toda, que pueda abarcar la diversidad del mundo que intenta guiar. La poesía exteriorista como dispositivo de reunión de todo lo que hace a lo humano se basa en la diversidad de sus posibilidades. Cardenal lo explica con una enumeración elocuente en el poema «Meditación en un DC-3»:

Para mí está diciendo:

Besuquear un bebé,

Pareja con caricias profundas,

Apretón de manos,

Palmadita en el hombro,

Lo humano tocando lo humano,

La unión de la piel humana con la piel humana

Es como tocar el Comunismo con el dedo compañeros. (57)

Esta enumeración de todo lo que representa la unión de los hombres en toda su humanidad muestra bien la adecuación de la poesía toda de Cardenal que se vuelve poesía total, porque se adecua en su forma a la idea de totalidad que intenta vehicular. Es poesía exteriorista y es poesía de lo humano, que en un movimiento crescendo aumenta gráficamente en el espacio y en la hoja, para ir de lo más inocente, representado por el bebé, hasta lo más complejo que se evoca con la idea de un comunismo tangible.

La escritura de Cardenal se presenta entonces como una poesía total, que intenta superarse para poder asumir plenamente su rol. Es una poesía construida con las manos, como un artesano trabaja la madera o la arcilla, y se inscribe entonces no solamente en la corriente exteriorista sino también en la historia de la revolución, porque como lo afirma el poeta en "La mano", "Todo lo que es hecho,/todo lo humano de la tierra es hecho por manos» (77). Los poemas de Vuelos de victoria aparecen como formas poéticas materiales que se adecuan a la progresión de la revolución en el díptico.

A medida que progresa la victoria profetizada, los poemas ganan en complejidad sin perder su fuerza enunciadora. El perfeccionamiento de la forma poética es particularmente visible en el poema «Visión de la ventanilla azul». En este poema el poeta adopta la focalización que le permite ver la revolución sandinista en $\mathrm{Ni}$ caragua desde los cielos. El color azul que recorre todo el poema simboliza tanto la utopía como la liberación y finalmente el amor humano. Este adjetivo, posicionado al final de los versos pone de relieve la idea de que estos valores representan la finalidad de la revolución y esto crea una armonía positiva en el discurso. De la misma manera, la aliteración en "-ella», que hace coincidir los términos «ella» y «bella», para hacer referencia a la tierra, contribuye a reforzar este equilibrio eufónico que confirma la idea de una utopía del amor no tan lejana. Aunque ciertos encabalgamientos recuerdan una lucha aun necesaria, evocada principalmente por términos como «explotación» $\mathrm{y}$ «combate», el principal elemento que se destaca por su posicionamiento gráfico es el sintagma «para el amor!». Este poema conclusivo 
transmite una mirada optimista en cuanto al futuro de Nicaragua, a pesar de todo lo sufrido, y este mensaje aparece como la expresión de una poesía total, que reúne equilibradamente todas las facetas del pensamiento cardenaliano en una forma que las refleja con absoluta coherencia.

Vuelos de victoria aparece así como un poemario que expone el proceso que asume el poeta en tiempos de revolución, para reunir en una poesía total sus convicciones literarias, religiosas, políticas y sociales. Los poemas de este volumen tienen un doble rol: por un lado recuerdan cronológicamente las vivencias de un pueblo que lucha por su liberación, y por el otro exponen un completo manejo del lenguaje poético en un crescendo de sofisticación poética. Este doble curso que se puede identificar en el poemario sublima la palabra poética de Ernesto Cardenal, que ya no es solamente profética, sino que funciona también como un espacio de memoria. El poeta lo explica en «Ocupados», cuando afirma:

Todo esto quedará para quien quiera verlo en los viejos

Periódicos

En periódicos amarillos al comienzo de la nueva historia

Periódicos poéticos. (33)

La poesía total de Ernesto Cardenal aparece entonces no sólo como una palabra profética para el campesinado sino como la voz del pasado, del presente y del futuro de Nicaragua. Una misión que el poeta parece haber aceptado desde sus primeros escritos y que ha guiado de manera insoslayable la totalidad de su obra.

\section{Referencias bibliográficas}

Borgeson, P. (1984). Hacia el hombre nuevo: poesía y pensamiento de Ernesto Cardenal. London: Tamesis Books Limited.

Cardenal, E. (1978). Lo que fue Solentiname. Nueva Sociedad, (35). Buenos Aires.

([1984] 2012). Vuelos de victoria. Madrid: Visor Libros.

Castiglione, M.E. (1990). “¿Para qué metáforas?» La poetica di Ernesto Cardenal. Firenze: La Nuova Italia.

Mereles Olivera, S. (2003). Cumbres poéticas latinoamericanas. Nicanor Parra y Ernesto Cardenal. Nueva York: Peter Lang.

Neruda, P. ([1935-1936] 1974). Caballo verde para la poesía. Verlag Detlev Auvermann KG (Kraus Reprint, Nendeln - Liechtenstein).

Hugo, V. [(1840) 1992]. Fonction du poète. Les rayons et les ombres, Euvres poétiques I, Paris: Gallimard.

Uriarte, I. (2000). La Poesía de Ernesto Cardenal en el proceso social centroamericano. Managua: Centro Nicaragüense de Escritores.

\section{Famin, Victoria}

